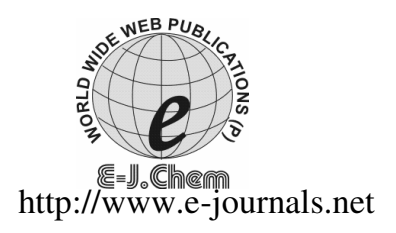

ISSN: 0973-4945; CODEN ECJHAO

E-Journal of Chemistry 2011, 8(1), 107-112

\title{
Chemical Analysis of Datura Metel Leaves and Investigation of the Acute Toxicity on Grasshoppers and Red Ants
}

\author{
NAVARATNARAJAH KUGANATHAN ${ }^{\# * *}$ and SASHIKESH GANESHALINGAM ${ }^{\#}$ \\ \# Department of Chemistry \\ University of Jaffna, Thirunelvely, Jaffna, Srilanka \\ *Department of Chemistry \\ University of Bath, Bath, BA2 7AY, England \\ nk247@bath.ac.uk
}

Received 9 May 2010; Accepted 20 July 2010

\begin{abstract}
The present study was carried out to analyse the inorganic and organic contents in the leaf of Datura metel and to investigate the acute toxicity at varying concentrations on grasshoppers and red ants. We determined the calcium, magnesium and phosphorous in the ionic state quantitatively and carried out screening tests and solvent extraction using chloroform to find out the presence of organic groups such as alkaloids, flavanoids, saponins and steroids. The concentration of $\mathrm{Ca}^{2+}, \mathrm{Mg}^{2+}, \mathrm{Fe}^{3+}$ and $\mathrm{PO}_{4}{ }^{3-}$ were found to be $(4.28 \pm$ $0.05) \times 10^{4},(3.86 \pm 0.009) \times 10^{4},(2.33 \pm 0.007) \times 10^{4}$ and $(4.65 \pm 0.06) \times 10^{4} \mathrm{ppm}$ respectively. The screening tests confirmed the presence of alkaloids and steroids and the absence of saponins and flavanoids. Increasing concentrations of the plant extracts $(2500-15000 \mathrm{ppm})$ were added to grasshoppers $(\mathrm{n}=10)$ and red ants $(n=10)$ in an experimental chamber. After 10 minutes of exposure, the numbers of live insects were counted. The results showed the $\mathrm{EC}_{50}$ value was $12000 \mathrm{ppm}$ for grasshoppers and $11600 \mathrm{ppm}$ for red ants. Percentage mortality increased from $20-60 \%$ with increasing concentrations. Our results indicated that extract of Datura metel leaves at higher concentrations was more toxic and it can be used as an insecticide against grasshoppers and red ants.
\end{abstract}

Keywords: Medicinal plant, Datura metel, Insecticide, Red ants, Grasshoppers

\section{Introduction}

Over the centuries, human beings have gathered information by trial and error. In ancient times humans used various plants and herbs that grew in their environment to treat various illnesses. Medicinal plants have emerged as some of the most widely studied plants and significant interest has been shown in their chemistry because of their potential application 
in medicine $e^{1-3}$. Many of these medicinal plants contain chemical constituents that could cause harmful effects to human if taken in large quantities. Alkaloids occurring in a large amount make these plants poisonous ${ }^{4}$. Large quantity of oxalic acid, a proto plasmic poison in the form of oxalates of calcium, sodium and potassium also produces poisoning ${ }^{5-7}$.

Some of these plants are poisonous to insects and pests ${ }^{8-10}$. There is a necessity to find cheap insecticides for the diverse needs of agriculture, destruction of house holds pests and prevention of vectors of diseases such as malaria in developing countries such as Sri Lanka and India. Plant based insecticides ${ }^{11,12}$. are preferred to chemical insecticide as they have little or no negative effect on the agricultural environment ${ }^{13}$. At present, there is not much knowledge of these plant based insecticides in the literature. The evidence suggests that plants containing a high percentage of rotenone ${ }^{14}$, powdered young leaves and twigs of Javanica (Blume) and nepalenis (Benn) are used to kill mosquito Larvae ${ }^{15}$.

In a quest to identify a plant based insecticide in this study we investigate the toxic effects of Datura metel, an indigenous medical plant used in ancient Indian medical system. In our previous study, we have shown that extract of Datura alba leaves at higher concentrations is more toxic and it can be used as an insecticide against aphids and ants ${ }^{16}$. Datura metel, which is under the family of solanaceae, is one of the most useful medicinal plant used in treating asthma, cough, burns and ulcer ${ }^{17}$. This plant grows in warmer parts of the world particularly in South and Southeast Asia including India and Sri Lanka. Datura metel is an annual, ash-green hairy species $0.40-1 \mathrm{~m}$ high. The leaves are $15 \mathrm{~cm}$ long and the flowers are purple in colour (Figure 1). Various parts of the plant (leaves, seeds, roots and fruits) are used for different purposes in medicine ${ }^{18}$.

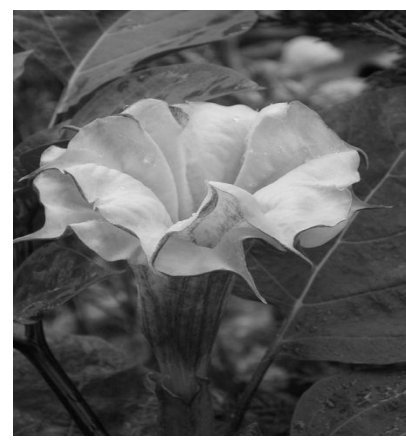

\section{Experimental}

Figure 1. Datura metel

The wet weight of the fresh Datura metel leaves was recorded before placing them in a hot air oven at $1000{ }^{\circ} \mathrm{C}$ for an hour for the complete evaporation of water. The sample was taken out, cooled and weighed to obtain the dry weight. This process was repeated until a constant weight was obtained.

\section{Total ash content}

Oven dried leaf sample was weighed in a porcelain crucible and ignited in a muffle furnace for several hours until a constant weight was obtained.

\section{Organic matter}

The difference between the weight of the oven dried sample and the ash was taken as the weight of the organic matter. 


\section{Calcium content}

$10.0 \mathrm{~mL}$ of test solution and $2 \mathrm{~mL}$ of $\mathrm{KOH}$ were added to a titration flask and stirred for $5 \mathrm{~min} 0.5 \mathrm{~g}$ of Patton reader's indicator and masking agent $(2 \mathrm{~mL})$ were added and the resulting solution was titrated against standard EDTA solution.

\section{Total calcium and magnesium content}

$10.0 \mathrm{~mL}$ of test solution was taken and $2 \mathrm{~mL}$ of buffer solution $(\mathrm{pH}=10), 2 \mathrm{~mL}$ of masking reagent were added and resulting solution was titrated against standard EDTA solution using Erichrome black $\mathrm{T}$ as an indicator.

\section{Phosphorous content}

Standard phosphorous solution (1000 ppm) was prepared. Different concentrations of solutions were made by using series of dilutions $(0-1000 \mathrm{ppm})$. A standard curve was obtained by plotting absorbance versus concentrations. Test solution $(5.0 \mathrm{~mL})$ was pippetted out and molybdate vanadate composite reagent $(5.0 \mathrm{~mL})$ was added to it and the resulting solution was mixed well and allowed to stand for 10 minutes. The intensity of the yellow colour developed was measured.

\section{Iron content}

Standard iron solution (1000 ppm) was prepared. Different concentrations of solutions were made by using series of dilutions $(0-30 \mathrm{ppm})$. A standard curve was obtained by plotting absorbance versus concentrations. Hydroxylamine hydrochloride $(10 \%, 2 \mathrm{~mL})$, distilled water $(1 \mathrm{~mL})$ and 1,10 ortho phenanthraline reagent $(2 \mathrm{~mL})$ were added to the test solution and the intensity of the red colour developed was measured.

\section{Qualitative Organic Analysis}

\section{Screening for saponins}

A small amount of the plant material was taken in a test tube and water was added. Then the plant material was shaken vigorously. The tube was observed over a period of one hour to find out whether there was any froth formation that indicates the presence of saponins.

\section{Screening for flavanoids}

Test solution $(15 \mathrm{~mL})$ was evaporated to dryness. The residue was defatted with petroleum ether, dissolved in rectified spirit $(2 \mathrm{~mL})$ and the solution was divided in to two equal parts in test tubes. To one portion concentrated $\mathrm{HCl}(0.5 \mathrm{~mL})$ and $\mathrm{Mg}$ turnings were added, cooled and shaken with butanol. The colour of the solution was compared with that in the second test tube.

\section{Screening for alkaloids}

The test solution $(70 \mathrm{~mL})$ was evaporated to dryness and $10 \mathrm{~mL}$ of $\mathrm{HCl}(2 \mathrm{~N})$ was added and heated in a steam bath for 5 minutes with stirring. This solution was then filtered. The filtrate was divided in to 4 equal portions in separate test tubes.

i) A few drops of Mayer's reagent were added to one of the test tubes. A creamed colour precipitate was observed. A yellow-creamish precipitate was observed.

ii) A few drops of Wagner's reagent were added to the solution in the second test tube. A brownish red precipitate was observed.

iii) The remaining two fractions were combined, basified with concentrated $\mathrm{NH}_{3}$ and the solution was extracted with $\mathrm{CHCl}_{3}$. The combined $\mathrm{CHCl}_{3}$ extracts were dried over anhydrous $\mathrm{MgSO}_{4}$ and concentrated. The solution was subjected to TLC with $\mathrm{CHCl}_{3}$ : $\mathrm{MeOH}=9: 1$ as the developing solvent. Then the plates were sprayed with dragondroff reagent. An orange colour precipitate was observed. 


\section{Screening for steroids}

Test solution $(15 \mathrm{~mL})$ was evaporated to dryness. The residue was stirred with petroleum ether $(10 \mathrm{~mL})$ and the organic layer was discarded. The residue was dissolved in $\mathrm{CHCl}_{3}$ $(10 \mathrm{~mL})$ and divided in to 3 equal portions in separate test tubes.

i) One of the test tubes was used as reference.

ii) The second test tube was held at an angle of $45^{\circ}$ and concentrated $\mathrm{H}_{2} \mathrm{SO}_{4}(2 \mathrm{~mL})$ was allowed to run along the side of the tube and observed for any changes. A yellow green fluorescent was observed.

iii) Acetic anhydride $\left(\mathrm{AC}_{2} \mathrm{O}\right)$ (3 drops) was added to the remaining portion and mixed. Then concentrated $\mathrm{H}_{2} \mathrm{SO}_{4}$ (1 drop) was added to this solution and mixed again. The colour changes were observed immediately and over a period of an hour.

\section{Extraction}

The leaves of Datura metel were collected from Northern part of Sri Lanka (Jaffna Peninsula). About $250 \mathrm{~g}$ of powdered leaves (dry) were extracted in a soxhlet extractor with chloroform $(500 \mathrm{~mL})$ as a solvent for $45 \mathrm{~h}$. The solvent was evaporated under pressure. A greenish brown colour semi solid (14.20 g) was obtained.

\section{Preparation of different concentrations}

Chloroform extract $(4.0 \mathrm{~g})$ was dried well using hot air oven to remove the trace amount of chloroform. After drying, four different weights of residue were weighed. Each of them was dissolved well in distilled water using magnetic stirrer and transformed to $100 \mathrm{~mL}$ volumetric flask. Then each of them was made up to the mark with distilled water.

\section{Toxicity of Datura metel on grasshoppers}

A clean well dried bottle was taken and it had ten grasshoppers which had the facility of air and young leaves of beans pasted with water as control or extract having concentration $2500 \mathrm{ppm}$. The system was in rest for 10 minutes. Number of live grasshoppers was counted. This was carried out in quadruplicates. Above procedure was repeated for different concentrations $(5000,10000$ and $15000 \mathrm{ppm})$ without changing the amount of young leaves of beans

\section{Toxicity of Datura metel on red ants}

A clean, well dried bottle was taken and it had ten red ants which had the facility of air and small amount of $D$-Glucose for controls (0) and mixed with extract having concentration $2500 \mathrm{ppm}$. The system was in rest for 10 minutes. Number of red ants killed, was counted. This was carried out in quadruplicates. Above procedure was repeated for different concentrations (5000, 10000 and $15000 \mathrm{ppm}$ ) without changing the amount of $D$-Glucose.

\section{Statistical analysis}

One-way ANOVA with Dunnett's post test was performed using GraphPad Prism version 5.00 for Windows, (GraphPad Software, San Diego California USA).

\section{Results and Discussion}

\section{Inorganic and organic analysis}

The moisture content of Datura metel was $76.69 \pm 0.12$. The carbon content as a measure of ash was $6.62 \pm 0.23$. The mean organic matter was $11.61 \pm 0.09$ (Table 1). 
Table 1. Quantitative measure of moisture, ash and organic matter of Datura metel

\begin{tabular}{cc}
\hline Contents & Amount, \% \\
\hline Moisture & $76.69 \pm 0.12$ \\
Ash & $6.62 \pm 0.23$ \\
Organic matter & $11.61 \pm 0.09$ \\
\hline
\end{tabular}

Calcium, magnesium, iron and phosphate contents were $(4.28 \pm 0.05) \times 10^{4}$, $(3.86 \pm 0.009) \times 10^{4},(2.33 \pm 0.007) \times 10^{4}$ and $(4.65 \pm 0.06) \times 10^{4} \mathrm{ppm}$ respectively (Table 2$)$.

Table 2. Quantitative measure of inorganic cations and anions

\begin{tabular}{cc}
\hline Ions & Amount, ppm \\
\hline $\mathrm{Ca}^{2+}$ & $(4.28 \pm 0.05) \times 10^{4}$ \\
$\mathrm{Mg}^{2+}$ & $(3.86 \pm 0.009) \times 10^{4}$ \\
$\mathrm{Fe}^{3+}$ & $(2.33 \pm 0.007) \times 10^{4}$ \\
$\mathrm{PO}_{4}{ }^{3-}$ & $(4.65 \pm 0.06) \times 10^{4}$ \\
\hline
\end{tabular}

In the chloroform extract, four organic constituents were tested for out of which only two were present (Table 3). Analysis of alkaloids and steroids was positive

Table 3. Organic constituents of Datura metel

\begin{tabular}{cc}
\hline Organic compound & Chloroform extract \\
\hline Flavanoids & - \\
Saponin & - \\
Alkaloids & + \\
Steroids & + \\
\hline \multicolumn{2}{c}{ - Absent; + Present }
\end{tabular}

Toxicity of Datura metel on grasshoppers and red ants

There was a significant dose dependent effect of Datura metel on the number of living grasshoppers $(\mathrm{P}<0.001)$ and red ants $(\mathrm{P}<0.01)$ (Figure 2). This indicates that high doses of leaf extracts are toxic.
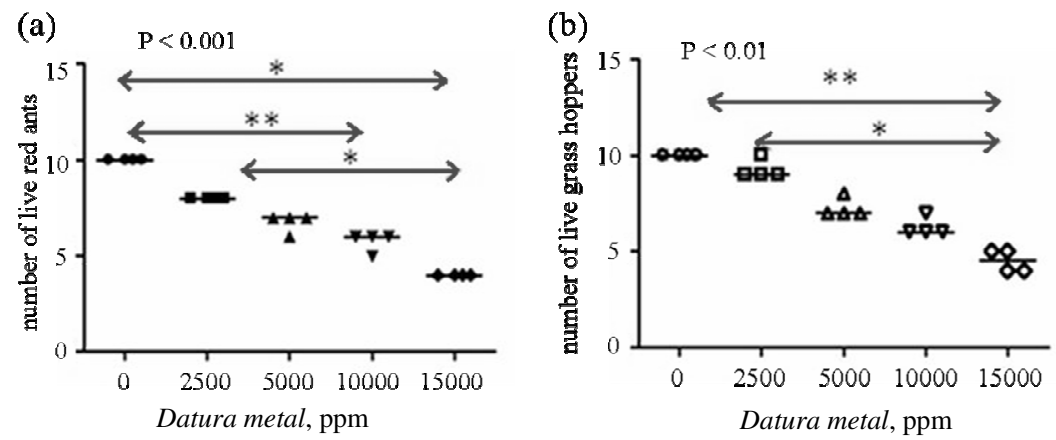

Figure 2. Scatter plot of dose dependent effect of Datura metel on the number of live (a) red ants; (b) grass hoppers in the experimental chamber. ANOVA; ${ }^{*}=\mathrm{P}<0.05,{ }^{* *}=\mathrm{P}<0.01$

The results showed the effective concentration $50 \%$ survival rate $\left(\mathrm{EC}_{50}\right)$ was $12000 \mathrm{ppm}$ for grasshoppers and $11600 \mathrm{ppm}$ for red ants. In the northern part of Sri Lanka, local farmers found that grasshoppers feed young leaves of beans. Also, various size ants were found in valuable vegetable plants (ladies finger, aubergine) before they were ready for harvest damaging its stem that attached to the vegetable. In addition, at homes red ants feed 
on variety of substances including sweets, starch and fats. Commonly available chemical insecticides are inorganic substances that are toxic to human and could dissolve in water and pollute the environment. Since water is often obtained from underground wells in these parts of the world, farmers are greatly interested in natural insecticides as they are organic compounds that cannot dissolve completely in water and hence pollute the environment to a lesser degree. These are also easily available and cheap. People are reluctant to use chemical insecticides at home as they can be toxic to the human body. In this regard, Datura metel was suggested to be an ideal candidate by the local farmers that lead to this project.

In this study, we have isolated and confirmed the presence of chemical constituents in the leaf of this plant and tested its toxicity on grasshoppers and red ants. Inorganic cations, anions, moisture, ash and organic matter were also determined quantitatively. The concentration of $\mathrm{Ca}^{2+}, \mathrm{Mg}^{2+}, \mathrm{Fe}^{3+}$ and $\mathrm{PO}_{4}{ }^{3-}$ were found to be $(4.28 \pm 0.05) \times 10^{4}$, $(3.86 \pm 0.009) \times 10^{4},(2.33 \pm 0.007) \times 10^{4}$ and $(4.65 \pm 0.06) \times 10^{4} \mathrm{ppm}$ respectively. The Initial screening test in this study confirmed the presence of alkaloids in the leaf extracts. Alkaloids in excessive amount could be poisonous. Hence we investigated the toxicity of this plant on grasshoppers and red ants. Experiments suggest a statistically significant dose dependent decrease in the survival rate and an increase in the percentage mortality of red ants and grasshoppers in the presence of Datura metel. These experiments suggest that extract of Datura metel at suitable concentration could potentially be useful to local farmers.

\section{Acknowledgment}

The authors would like to thank the support of technical staff in the Department of Chemistry, University of Jaffna, Sri Lanka. Late Mr. K. S. Kugathasan and Dr. S. Varnakulasingam are acknowledged for their useful discussions.

\section{References}

1. Briskin D P, Plant Physiol., 2000, 124, 507-514.

2. Pandey M M, Rastogi S and Rawat A K S, J Ethnopharmacology, 2007, 110(3), 379-390.

3. Chabert P, Attioua B and Brouillard R, Biofactors., 2006, 27, 69-78.

4. Gardner D R and Pfister J A, Rangeland Ecol Manag., 2007, 60, 441-446.

5. Doaigey A R, Am J Bot., 1991, 78, 1608-1616.

6. Creasy R, The edible flower garden. Periplus Editions (HK) Ltd., Singapore, 1999.

7. Cousins D, Int Zoo Yearbook, 2006, 40, 341-350.

8. Sahaf B Z, Moharramipour S and Meshkatalsadat, M H, Insect Sci., 2007, 14, 213-218.

9. Sener B, Bingol F, Erdogan I, Bowers W S and Evans P H, Pure Appl Chem., 1998, 70, 403-406.

10. Roger C R, Integrated Pest Management Rev., 1997, 2, 25.

11. Jacob G, Pal B H and Ravishankar GA, Crit Rev Biotechnol., 2000, 20, 49-77.

12. Greenberg S M, Showler A T and Liu T X, Insect Sci., 2005, 12, 17-23.

13. Isman M B, Annu Rev Entomol., 2006, 51, 45-66.

14. Nivsarkar M., Cherian B and Padh H, Curr Sci., 2001, 81, 667-672.

15. Chopra R N, Chopra's Indigenous Drugs of India. Academic Pub, New Delhi, 2006.

16. Kuganathan N, Saminathan S and Muttukrishna S, Internet J Toxicol., 2008, 5, 2.

17. Alagesapoobathi C, Afr J Trad CAM., 2009, 6(3), 222-227.

18. Nadkarni K M, Indian Materia Medica, Popular Prakashan, Bombay, 1976. 


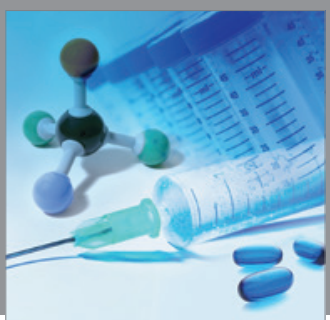

International Journal of

Medicinal Chemistry

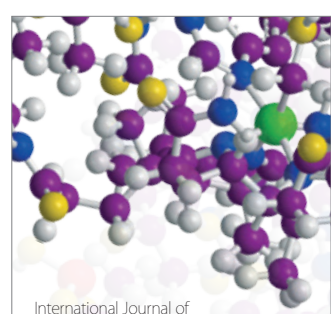

Carbohydrate Chemistry

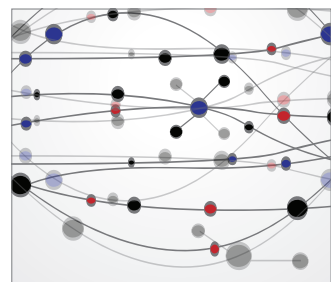

The Scientific World Journal
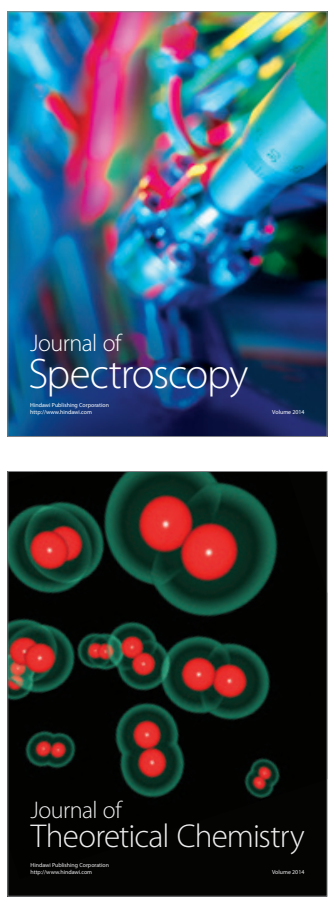
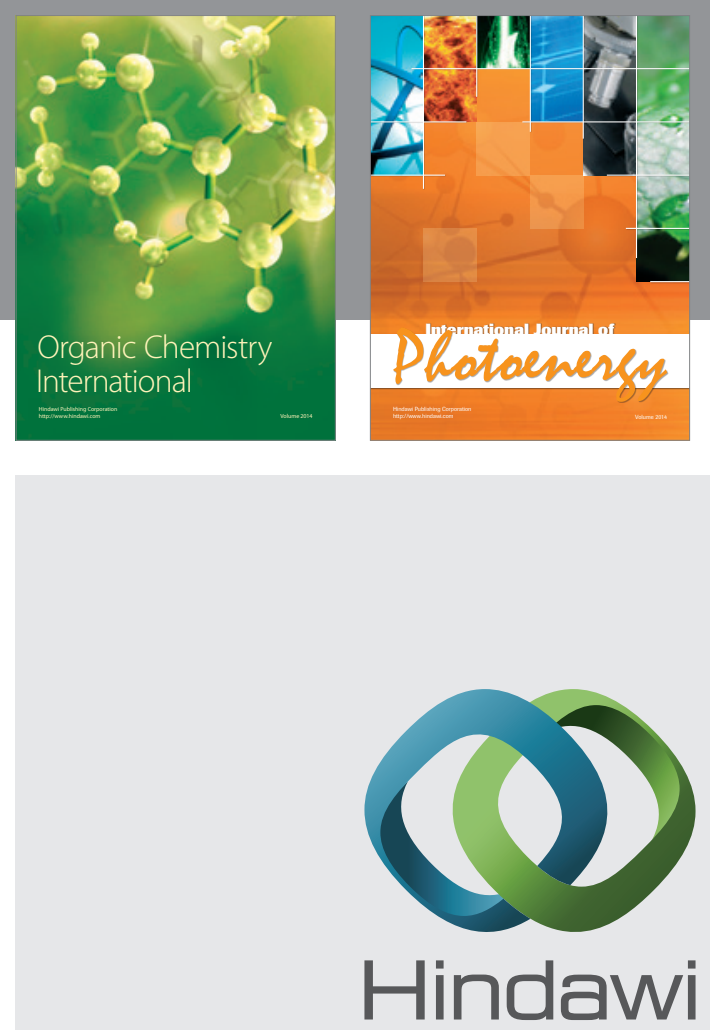

Submit your manuscripts at

http://www.hindawi.com
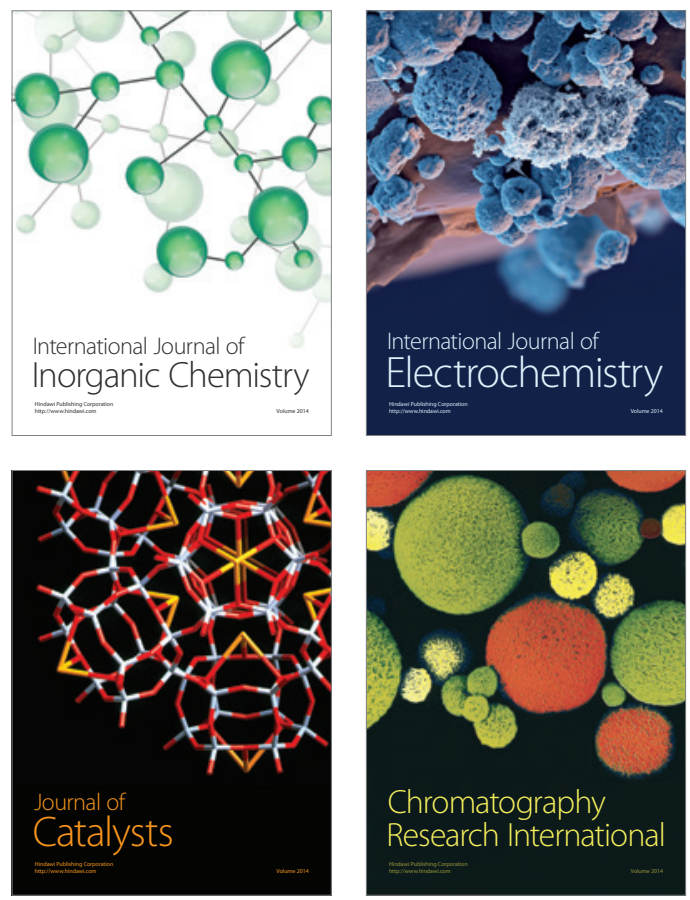
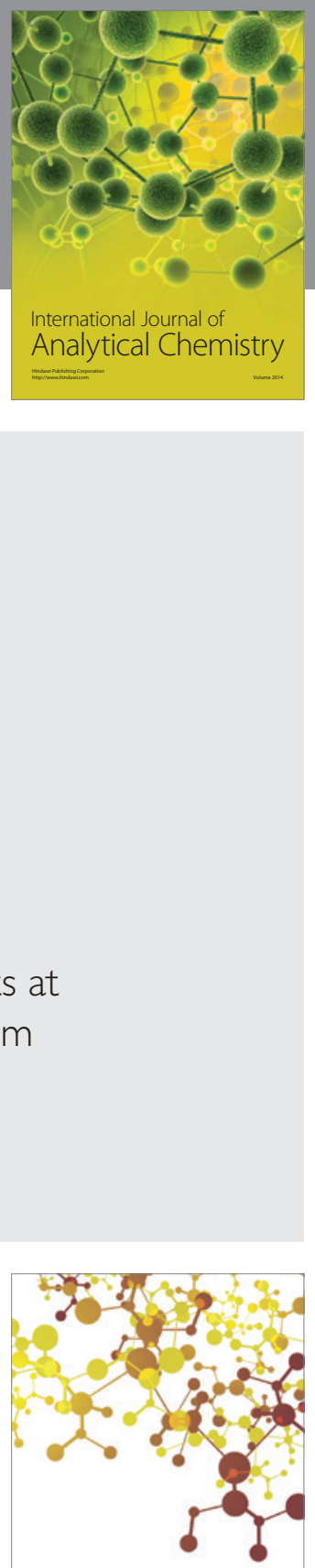

Journal of

Applied Chemistry
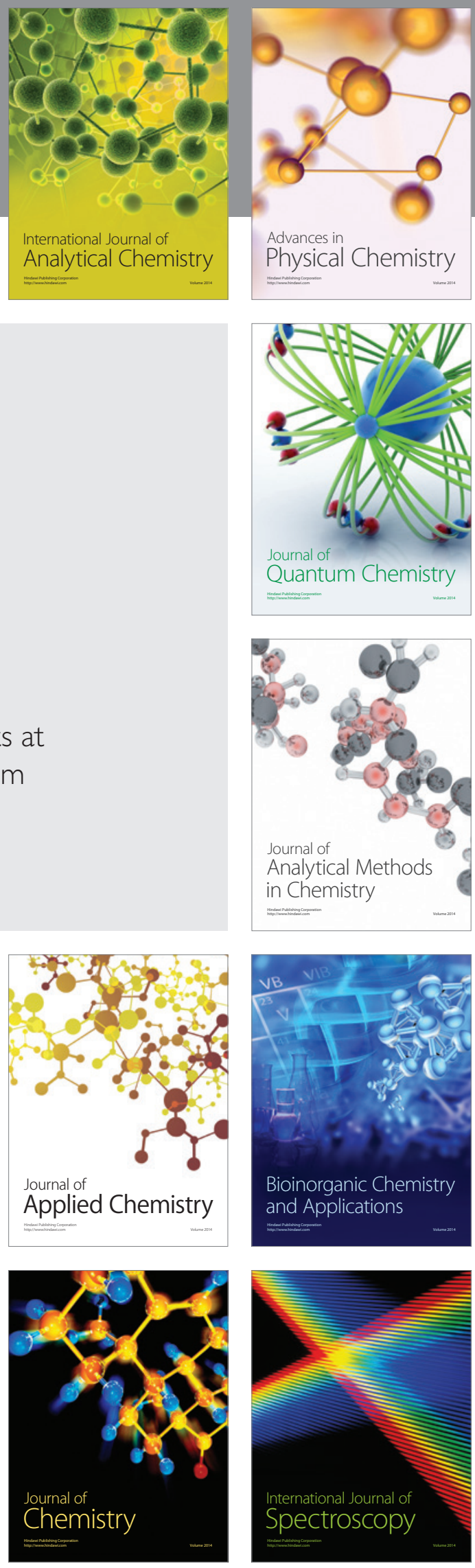